\title{
Neuromuscular Performance in Normal and Anterior Cruciate Ligament-Deficient Lower Extremities*
}

\author{
Edward M. Wojtys, $†$ MD, and Laura J. Huston, MS
}

From MedSport at the University of Michigan, Ann Arbor, Michigan

\begin{abstract}
The neuromuscular function of the lower extremity in $\mathbf{4 0}$ normal and 100 anterior cruciate ligament-deficient volunteers was evaluated by physical examination, KT1000 arthrometer measurements, isokinetic strength and endurance testing, subjective functional assessment, and an anterior tibial translation stress test. A specially designed apparatus delivered an anteriorly directed step force to the posterior aspect of the leg while anterior tibial translation was monitored and electromyographic signals were recorded at the medial and lateral quadriceps, medial and lateral hamstrings, and gastrocnemius muscles. Testing was done at $30^{\circ}$ of knee flexion with the foot fixed to a scale to monitor weightbearing, while the tibia remained unconstrained. Results indicate that muscle timing and recruitment order in response to anterior tibial translation are affected by anterior cruciate ligament injury. These alterations in muscle performance change with time from injury, correlate with an individual's physical activity level, affect subjective functional parameters, and are directly related to the degree of dynamic anterior tibial laxity seen with stress testing.
\end{abstract}

Over the last 25 years, a tremendous research effort has been focused on the biomechanics of the ACL. ${ }^{13,15,29,30,42,46,51-53,76}$ The principles learned have been applied clinically in the hope of improving the natural history of a knee with an injured ACL. In fact, impressive strides in treatment have followed the course of ACL research. A torn ACL in an athlete is not necessarily the

\footnotetext{
*Presented at the 18th annual meeting of the AOSSM, San Diego, California, July 6, 1992

$\dagger$ Address correspondence and reprint requests to: Edward M. Wojtys, MD, MedSport, POB 363, Ann Arbor, MI 48106.

No author or related institution has received any financial benefit from a product named or used in this study.
}

"beginning of the end," as it was once described. ${ }^{75}$ The prognosis for an athletic individual with an ACL injury with proper care appears to be much improved, at least over the short term. ${ }^{16,56}$

Despite these clinical and biomechanical advances, our current information base does not explain the functional status of several types of individuals with increased anterior laxity of the knee. One of these types is the athlete who has excess anterior laxity but who functions at a very high level of activity without evidence of instability. ${ }^{54,57,78}$ Some of these athletes have normal ligaments that are just not as tight as most, while a few represent asymptomatic ACLdeficient (ACL-D) extremities. Despite a lack of passive restraint, no instability is apparent, and a high level of function is maintained. Secondly, there is the individual who has had an ACL reconstruction and has returned to a high level of activity without instability in spite of considerable residual anterior laxity. Paradoxically, there are those whose laxities are within "normal parameters" yet in whom symptoms of instability persist. ${ }^{22}$ These examples emphasize the dual nature of knee stability: the passive restraint system, which is composed primarily of ligaments and capsule, and the dynamic system, which is composed of the neuromuscular elements. The interaction between the dynamic and static systems remains unclear. An improved understanding of the neuromuscular component of stabilization is needed to augment our treatment of injuries to the passive restraints of the knee.

This investigation was not performed to alter the current standards in decision-making regarding nonoperative versus operative treatment of ACL tears. These decisions should be made based on the age and activity level of the subject while keeping in mind the known risk factors for degenerative disease. This research was designed to augment both directions of treatment by maximizing the potential of the neuromuscular control system. This was attempted by studying the neuromuscular response to anterior tibial translation (ATT) in a specifically designed apparatus that allowed monitoring of spinal reflexes and cortical control activity. Unfortunately, at this time, we do 
not fully understand the complexities of dynamic knee joint control, which makes the interpretation of this data difficult and subject to criticism.

\section{BACKGROUND}

In 1944, Ivar Palmar ${ }^{62}$ wrote about the theory that ligaments supply the central nervous system (CNS) input that makes neuromuscular control of knee joints possible. Several years later, in 1956, Cohen and Cohen ${ }^{18}$ popularized the idea of an "arthrokinetic reflex." Based on their work with decerebrate cats, they suggested that the origin of important protective afferent input was the knee joint capsule. Cohen and Cohen decided that a quadricepshamstrings tension balance was necessary for knee joint stability. Andersson and Stener ${ }^{2}$ concurred with Cohen and Cohen's work after localizing important mechanoreceptors in the anteromedial region of the cat knee joint capsule. Subsequently, Petersen and Stener ${ }^{63}$ suggested that these capsular receptors were not mechanoreceptors but merely nociceptors responding to large joint loads. These capsular receptors were later shown to be sensitive to very low joint pressures and to tensile loads in the range of fractions of Newtons. ${ }^{17,36}$

In hopes of isolating the origin of proprioceptive afferent input, several neuroanatomic studies have focused directly on the ACL. Kennedy et al. ${ }^{41}$ isolated free nerve endings in Golgi-like receptors in the synovium covering the ACL. Schultz et al. ${ }^{71}$ found these same receptors on the surface of the ACL beneath the synovial sheath. Schutte et al. ${ }^{72}$ described an extensive network of sensory receptors in the ACL, including Pacinian and Ruffini corpuscles and free nerve endings. Gomez-Barrena et al ${ }^{32}$ isolated direct neural pathways from the ACL to spinal ganglia by using tracers to study axonal transport.

Despite these anatomic advancements, the precise origin of the afferent input needed to protect specific ligaments and maintain joint stability is still not agreed on. , $^{3,25,61,65,73}$ In 1987 Solomonow et al. ${ }^{73}$ reported a direct ligamentmuscle reflex arc from their work with ACLs in cats and humans. They suggested that ACL injury in humans interrupts this ligament-muscle reflex arc, triggering a second slower pathway needed to modulate the quadriceps and hamstrings muscles from muscle and capsular receptors. In a comparison of normal and ACL-D human extremities, Solomonow et al. were able to show a substantial difference in the EMG activity of the ACL agonist hamstring muscles when the ACL was severed. The meaning of these EMG changes remains in question.

Electromyographic work by Draganich et al. ${ }^{20}$ with six male subjects with ACL-D extremities also suggested that the hamstrings act synergistically with the ACL. Specifically, they reported increased EMG activity in the biceps femoris muscle from $30^{\circ}$ to $0^{\circ}$, which is precisely where ACL force and strain increase. ${ }^{14,15,70,76}$

In contrast, work done recently by Pope et al. ${ }^{65}$ in 1990 questioned the existence of a direct ligament-muscle reflex arc; they attributed the activity in the posterior articular nerve of cats after tugging on the ACL to receptors in the periarticular tissues not in the ligament itself. Interest- ingly, recent work by Pitman et al.$^{64}$ continues this debate. By using an arthroscope in vivo, they demonstrated somatosensory-evoked potentials (SSEP) in the cerebral cortex after direct electrical stimulation of an intact ACL in nine patients. The SSEPs represent proprioceptive input from peripheral nerves transmitted along the posterior columns.

While a direct ligament-muscle protection system may be difficult to demonstrate in all animal and human models in all joint positions, there is increasing evidence that supports a modulating system of knee joint afferent input on motoneuron output. Alpha motoneurons are affected by both high ${ }^{24}$ and low $^{37,48}$ threshold joint afferents. Flexor reflex pathways, ${ }^{24}$ Ia interneurons, ${ }^{26,33}$ and Ib interneurons ${ }^{48}$ have all demonstrated the capability of modulating different efferent pathways.

Even though a precise diagram of the neurocircuitry of dynamic knee joint control is not yet agreed on by investigators, there is no doubt that the neuromuscular system is capable of altering the strains imposed on the passive restraints of the knee. ${ }^{70}$ White and Raphae ${ }^{80}$ reported that a quadriceps contraction could reduce the strain produced in the medial collateral ligament when a valgus force was applied to the knee. Goldfuss et al. ${ }^{31}$ showed that the stiffness of the medial side of the knee could be increased up to 48\% with contraction of the quadriceps and hamstring muscles. Renström et al. ${ }^{70}$ used cadavers and a Hall effect transducer to show that the hamstring muscles could decrease ACL strain in all positions tested.

Timely muscle contraction, or "dynamization" of the tibiofemoral joint, adds a new dimension to the concept of knee joint stability. It is this juxtaposing of the joint surfaces through muscle contraction or loadbearing that allows the geometry of the tibiofemoral joint to become an integral part of joint stability. ${ }^{38}$ In the unloaded knee, which does not mimic most ligament injury situations, all externally applied forces or moments are internally resisted by ligaments and capsule. ${ }^{15}$ When the knee joint is subjected to axial loading, joint contour becomes an important stabilizing factor that is frequently underappreciated. Markolf et al. ${ }^{50}$ tested axial joint loads up to $925 \mathrm{~N}$ at $0^{\circ}$ and $20^{\circ}$ of knee flexion in cadavers to demonstrate the stabilizing effect of joint contact force; their work in wellconditioned athletes showed a tenfold increase in knee joint stiffness with muscle contraction. Work done by Wang and Walker, ${ }^{79} \mathrm{Hsieh}$ and Walker, ${ }^{38}$ and Olmstead et al. ${ }^{59}$ concurred with the findings of Markolf et al. Wang and Walker demonstrated an $80 \%$ reduction in rotatory laxity with 938 $\mathrm{N}$ of compressive force. This stabilizing capacity is important for activities of daily living as well as for physically demanding sports.

When an injury occurs to the passive restraint system, new demands are placed on dynamic restraints, and retraining becomes the key to adaptation. Abbott et al., ${ }^{1}$ in their extensive review of knee ligament injuries, stated that ligaments are the first link in the kinetic chain that provides rich sensory input to the nervous system. Fortunately, the neuromuscular "servomechanism" that modulates hamstring-quadriceps activity is truly dynamic. The 
central nervous system processes incoming afferent proprioceptive input by comparing actual movement with intended performance. ${ }^{67}$ The discrepancy between actual and desired movement then can trigger efferent output to correct the error (servocontrol).

Brand ${ }^{12}$ and Wroble and Brand ${ }^{81}$ questioned the traditional view of ligaments as merely mechanical restraints and speculated that the neurosensory function of the ligaments may, in fact, approach that of their mechanical effect. Because voluntary movements initiated at the cerebral cortex may be too slow to prevent injury, ${ }^{55,66}$ questions exist about short loop (spinal) reflexes that may be capable of a more timely response. ${ }^{48}$ Triggering protective spinal reflexes during a dangerous maneuver may play an even greater role in knee joint stabilization than the voluntary response. ${ }^{67,69}$ Regardless of where the afferent input originates, a timely protective response is the key to knee joint protection in the injury situation.

\section{MATERIALS AND METHODS}

\section{Subjects}

Forty healthy, athletically active volunteers (26 men and 14 women) with no known knee injuries served as the normal control group; the average age was 23.5 years. One hundred consecutive ACL-D individuals ( 70 men and 30 women) who were identified by athletic trainers and physicians were tested; the average age was 25.7 years. All ACL tears had been arthroscopically documented. Initially, no attempt was made to eliminate combination ligament injuries or those with chondral or meniscal problems; however, all of these individuals were considered to be "recovered" from the injuries before their participation in this study. To be included in the study, individuals were required to perform an isokinetic strength test with no more than minimal discomfort. Those with significant discomfort from underlying knee problems were excluded. Neither the physicians' recommendations for treatment nor the individuals' selection of nonoperative versus operative treatment were used as selection criteria. Success of treatment did not affect participation in this study. Several ACL-D individuals were highly successful intercollegiate athletes, while others could not walk without episodes of giving way.

The ACL-D individuals were subdivided into three groups based on the time from ACL injury to evaluation. In the acute injury group, the duration of time was less than 6 months. In the semiacute injury group the duration of time was 6 to 18 months, and in the chronic injury group it was greater than 18 months. All individuals had a physical examination; a subjective functional evaluation including activity level, pain, swelling and giving way ${ }^{56}$; KT-1000 arthrometer measurements; isokinetic dynamometer evaluation of knee flexion and extension peak torque and endurance testing at $60^{\circ}$ and $240^{\circ}$ per second; and a knee joint stress test on a specifically designed apparatus. The subjective evaluation ${ }^{56}$ was used to subdivide each time group (acute, semiacute, and chronic groups) into best and worst subsets.

\section{Knee testing apparatus}

The testing apparatus was designed to measure ATT in reference to the femur in response to an anteriorly directed 30-pound step force applied to the posterior aspect of the leg, while lower extremity muscle function was recorded using surface EMG at five muscle locations. The induced ATT stimulated efferent activity originating at both the spinal cord and cortical level. Because the anteriorly directed force was applied to the gastrocnemius muscle belly, care was taken to ensure that motion artifact and the effects of muscle deformation were not confused with a spinal level reflex to the gastrocnemius muscle in response to the displacement. This was accomplished by several trials with and without a windowed short leg cast in place. This model allowed for ATT but would not permit gastrocnemius deformation, allowing differentiation of these two factors. Also, it is important to note that the displacing force was applied identically in every trial. Therefore, if the gastrocnemius EMG activity detected was caused by the direct stimulation of the device, the EMG pattern should have been nearly the same in each trial, but in fact it varied significantly.

During testing, the individuals were comfortably positioned with the knee maintained at $30^{\circ}$ of flexion by vertical adjustment of an ischial support specifically designed to allow uninhibited hamstring muscle activity (Fig. 1). The foot was fixed with the ankle at $10^{\circ}$ to $15^{\circ}$ of dorsiflexion on a standard scale to monitor the weightbearing status that was maintained in the 20 - to 30 -pound range. Tibial translations, rotations, and subluxations were not restrained in any way. Two linear potentiometers were employed to measure ATT (Fig. 1). Relative tibial displacement was quantified by placing one potentiometer on the patella with the second placed on the tibial tuberosity.

A validation study comparing the accuracy of the KT1000 arthrometer with this system was performed using machined aluminum plates of known differentials. ${ }^{44}$ In this in vitro setting, the correlation coefficient between the KT1000 arthrometer and the dual linear potentiometers was 0.98; however, it is important to note that differences exist in the degree of sensitivity of each device. The dual potentiometer system was accurate to $0.01 \mathrm{~mm}$ throughout a full range of displacements $(-20.00$ to $20.00 \mathrm{~mm})$, while the KT-1000 arthrometer measurement was accurate to 0.16 $\mathrm{mm}$ with a much higher level of variability. ${ }^{44,77,82}$

\section{Electromyographic recordings}

Surface EMG recordings were taken from five locations: lateral quadriceps, medial quadriceps, lateral hamstrings, medial hamstrings, and gastrocnemius muscles. Surface electrodes produced more reproducible and repeatable recordings than indwelling wire electrodes in previous testing by Kadaba et al ${ }^{40}$ Bipolar electrodes (Hewlett-Packard, Waltham, MA) were consistently placed over the midregion of each muscle group oriented along the muscle belly, $3 \mathrm{~cm}$ apart. Before electrode placement, the skin was prepared with sandpaper and cleaned with isopropyl alcohol to ensure adequate surface contact. The raw EMG signal was 


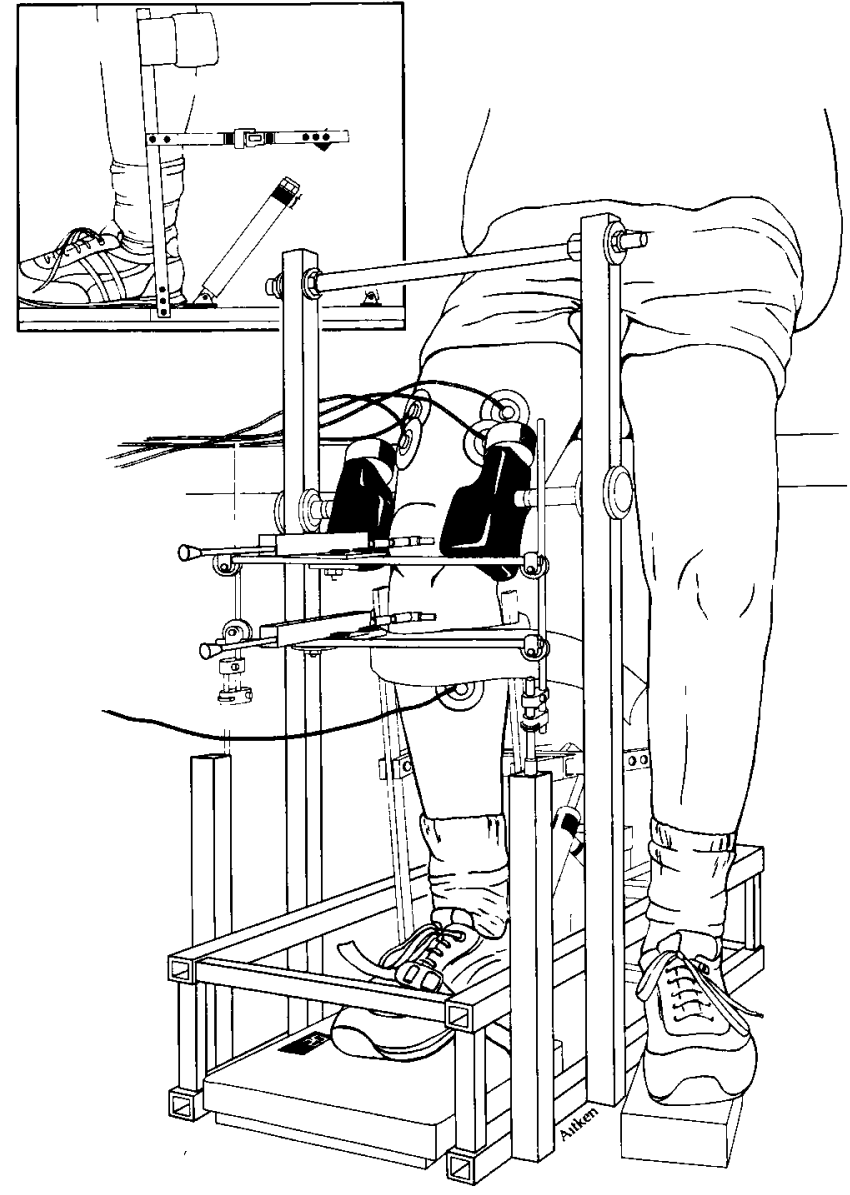

Figure 1. Anterior tibial translation testing device with EMG monitoring of gastrocnemius, quadriceps, and hamstrings muscles.

amplified at $100 \mu$ volts/volt and fed into a Zenith Data Systems 286 computer (Zenith Data Systems Corp., St. Joseph, MI) for storage and data analysis. The EMG recordings were sampled at a frequency rate of $1000 \mathrm{~Hz}$ over a 2.5-sec time window beginning with the onset of the anteriorly directed force.

\section{Testing protocol}

The ACL-D individuals always had the uninvolved extremity tested first, while the normal volunteers followed no set pattern. After a brief orientation, during which the anteriorly directed step force was applied to the extremity several times, two types of tests were performed. A relaxed test was performed by asking individuals to relax their muscles while the force was applied. If muscle activity was detected on EMG at the start of the test, it was not used, and the test was repeated. A response test was performed by asking individuals to resist the anterior tibial force after they sensed its onset. Ten trials of each test were recorded and then averaged. Any trial in which the individual contracted the leg musculature before the anterior force was applied was repeated. To prevent anticipation of anterior force application, randomized time intervals (ranging from 0.1 to
$10 \mathrm{sec}$ ) were used before force application. All visual and audio clues associated with the force application were eliminated.

\section{Reproducibility evaluation}

A pilot study was conducted to determine the magnitude of trial-to-trial (within a test), test-to-test (within a day), and day-to-day variability of both EMG and ATT measurements in normal individuals. These results formed the basis of the statistical differences reported for the normal control group and ACL-D individuals.

Five normal individuals ( 3 women and 2 men) were selected and tested on 4 alternating days with 4 tests per day. All trials were conducted by 1 examiner. A single test consisted of 10 consecutive relaxed and 10 consecutive response trials. The ATT and 5 EMGs (lateral quadriceps, medial quadriceps, lateral hamstrings, medial hamstrings, and gastrocnemius muscles) were recorded. The individual was positioned in the testing apparatus according to the standard protocol. Between tests, the individual was taken out of the testing device, and all surface electrodes were removed. After a period of 30 minutes, new electrodes were applied, and the individual was repositioned and retested.

Three-factor analysis of variance found no significant differences between trials or between tests for all parameters. Differences in reflex (spinal) reaction times were not significant; however, a significant difference was found between days for both ATT and voluntary muscle reaction time (MRT). The magnitude of the expected measurement variability was expressed by computing $95 \%$ confidence limits: ATT $( \pm 0.3 \mathrm{~mm})$, gastrocnemius ( $\pm 2.5 \mathrm{msec})$, lateral hamstring ( $\pm 5.5 \mathrm{msec})$, medial hamstring $( \pm 5.9 \mathrm{msec})$, lateral quadriceps $( \pm 4.6 \mathrm{msec})$, and medial quadriceps $( \pm 5.4$ msec) muscles. These "expected variations" were then used to determine statistical significance in all other comparisons of ATT and MRT.

Although not significant, it was noted that the ATT values for the relaxed test were consistently lower during the first 3 to 4 trials of the initial test as compared with the remaining and subsequent tests. A series of 5 to 7 "pretrials" was routinely used to allow the individual to become acclimated to the testing device and to allow the ATT time to equilibrate.

\section{Data analysis}

The MRTs were calculated by measuring the time delay between the onset of the 30-pound stimulus and muscle activity. Three regions of the EMG signal were analyzed after movement artifact was identified by pattern recognition and were disregarded in the data analysis (especially in the gastrocnemius EMG recordings). Attention was focused on spinal cord reflex, intermediate response, and voluntary muscle activity..$^{23,43}$ Each of these responses has specific time and shape characteristics that were used to identify these portions of the EMG recording after ATT; electrical stimulation was not used in this study. Mechanically and electrically evoked somatosensory potentials have been compared in human upper extremities by Pratt 
TABLE 1

Activity level, strength, displacements, and subjective evaluation versus time from injury

\begin{tabular}{|c|c|c|c|c|c|c|c|}
\hline & \multirow{2}{*}{ Normal } & \multicolumn{2}{|c|}{ Chronic } & \multicolumn{2}{|c|}{ Semiacute } & \multicolumn{2}{|c|}{ Acute } \\
\hline & & Best & Worst & Best & Worst & Best & Worst \\
\hline Activity level ${ }^{a}$ & 5.6 & $8.5^{b}$ & 4.1 & 6.6 & 6.0 & $9.4^{b}$ & 5.8 \\
\hline \multicolumn{8}{|l|}{ Strength $^{c}$} \\
\hline Quadriceps & 86.0 & $86.4^{b}$ & 57.0 & $72.4^{b}$ & 59.6 & $85.6^{b}$ & 63.7 \\
\hline Hamstrings & 47.1 & $50.9^{b}$ & 34.8 & 50.9 & 41.3 & 48.6 & 42.2 \\
\hline \multicolumn{8}{|l|}{ Displacement (mm) } \\
\hline Tensed & 2.1 & $3.9^{b}$ & 6.6 & $4.1^{b}$ & 6.8 & 4.5 & 5.5 \\
\hline Relaxed & 5.4 & 11.8 & 13.1 & 10.2 & 10.5 & 13.0 & 12.3 \\
\hline Subjective evaluation score & & $91.0^{b}$ & 36.3 & $88.8^{b}$ & 42.4 & $62.4^{b}$ & 32.8 \\
\hline Pain & & $80.0^{b}$ & 32.5 & $68.0^{b}$ & 36.0 & $58.0^{b}$ & 30.0 \\
\hline Swelling & & $92.5^{b}$ & 38.8 & $100.0^{b}$ & 46.0 & $58.0^{b}$ & 36.0 \\
\hline Partial giving way & & $82.5^{b}$ & 32.5 & $80.0^{b}$ & 40.0 & $44.0^{b}$ & 30.0 \\
\hline Full giving way & & $100.0^{b}$ & 38.8 & $100.0^{b}$ & 46.0 & $76.0^{b}$ & 34.0 \\
\hline
\end{tabular}

${ }^{a} 10=$ Competitive jumping, turning, twisting sports.

8 = Recreational jumping, turning, twisting sports.

6 = Jog, bike, swim, occasional pivoting sports.

4 = No jumping, turning, twisting sports; swim, bike, jog regularly.

$2=$ No jumping, turning, twisting, occasional jog, swim, bike.

$0=$ Couch potato.

${ }^{b}$ Significant difference at $P=0.05$ level; in each subgroup best is compared with worst. Best and worst are determined by subjective evaluation. Chronics are best/worst $15 \%=8 / 50 ;$ semiacutes are best $/$ worst $25 \%=5 / 20 ;$ and acutes are best $/$ worst $15 \%=5 / 30$.

${ }^{c}$ Strength $=($ Peak torque $/$ Body weight $) \times 100 \%$.

TABLE 2

Muscle recruitment preference (in percent) in response to anterior tibial translation (response test)

\begin{tabular}{|c|c|c|c|}
\hline & $\begin{array}{c}\text { Hamstrings } \\
\text { 1st }\end{array}$ & $\begin{array}{l}\text { Quadriceps } \\
\text { 1st }\end{array}$ & $\begin{array}{c}\text { Gastrocnemius } \\
\text { 1st }\end{array}$ \\
\hline \multicolumn{4}{|l|}{ Normal (control) } \\
\hline $\mathrm{SC}^{\alpha}$ reflex & 14 & 16 & 70 \\
\hline Intermediate & 45 & 28 & 28 \\
\hline Voluntary & 48 & 35 & 17 \\
\hline \multicolumn{4}{|l|}{$\begin{array}{c}\text { Combined ACL } \\
\text { group }\end{array}$} \\
\hline SC reflex & 21 & 14 & 65 \\
\hline Intermediate & 51 & 37 & 11 \\
\hline Voluntary & 39 & 38 & 23 \\
\hline \multicolumn{4}{|l|}{$\begin{array}{c}\text { Acute ACL } \\
\text { injuries }\end{array}$} \\
\hline $\mathrm{SC}$ reflex & 19 & 13 & 68 \\
\hline Intermediate & 30 & 56 & 15 \\
\hline Voluntary & 27 & 49 & 24 \\
\hline \multicolumn{4}{|l|}{$\begin{array}{c}\text { Semiacute ACL } \\
\text { injuries }\end{array}$} \\
\hline SC reflex & 33 & 10 & 57 \\
\hline Intermediate & 65 & 20 & 15 \\
\hline Voluntary & 25 & 40 & 35 \\
\hline \multicolumn{4}{|l|}{$\begin{array}{l}\text { Chronic ACL } \\
\text { injuries }\end{array}$} \\
\hline SC reflex & 18 & 15 & 67 \\
\hline Intermediate & 60 & 32 & 8 \\
\hline Voluntary & 52 & 30 & 18 \\
\hline
\end{tabular}

a Spinal cord.

et al. ${ }^{68}$ In general, mechanically induced potentials were of lower amplitude and contained fewer components, suggesting that the electric stimulus activated more fibers synchonously. There was less temperal dispersion with the mechanical potentials, suggesting that they originated from a more uniform fiber population.

The initial spinal cord reflex appears to be monosynaptic, bypasses muscle spindle receptors, resembles a tendon tap reflex on manual physical examination, ${ }^{43}$ and it occurred between 20 and $119 \mathrm{msec}$ after the onset of ATT in this study. The large range in reflex response time may be explained by the level of presynaptic inhibition present and by the level of motoneuron excitability. This initial spinal reflex on the EMG recording was usually monophasic, while the amplitude was approximately $5 \%$ of that seen in voluntary activity. The initial spinal level response appears to be similar to an $\mathrm{H}$-reflex that requires an electric stimulus to be delivered to the afferent nerve in a reflex arc, sufficient to depolarize the large sensory fibers but insufficient to activate the smaller motor fibers. Deschuytere et al. ${ }^{19}$ have previously recorded H-reflex activity from the quadriceps, hamstrings, and gastrocnemius muscles.

During the early phase of ATT, if the motor nerves are depolarized instead of the sensory fiber, and antidromic conduction occurs along the motor nerve, a biplasic response of larger amplitude similar to an F-wave (electrical stimulation) may result. ${ }^{43}$ During preliminary testing, the possibility that this response was generated solely by a direct stimulation of the muscle fibers was ruled out by the application of a short leg cast and by repeat testing. The cast allowed ATT but did not allow deformation of the gastrocnemius muscle.

The intermediate response appears to be a spinal reflex with interneuronal input from centers higher than the spinal cord and resembles the late response produced electrically. ${ }^{23}$ It is very reproducible, occurring between spinal cord and voluntary activity. This response is biphasic, larger in amplitude than the spinal cord reflex but smaller in amplitude than voluntary activity and routinely occurs just before voluntary activity (130 to $170 \mathrm{msec}$ ). Interestingly, Pitman et al. ${ }^{64}$ reported SSEP occurring with 38.6 to $81.6 \mathrm{msec}$, which may represent the afferent portion of this loop if the signal reached the cerebral cortex.

Voluntary muscle activity was identified by the time of occurrence ( 220 to $360 \mathrm{msec}$ ) and pattern of activity. It was always biphasic, of the largest amplitude and of longest duration. 
TABLE 3

Muscle timing in response to anterior tibial translation normal (control) group

\begin{tabular}{|c|c|c|c|}
\hline & \multicolumn{3}{|c|}{ Dominant vs. nondominant extremities average response times ( $\mathrm{msec}$ ) } \\
\hline & Dominant & Nondominant & Difference \\
\hline \multicolumn{4}{|l|}{$\mathrm{SC}^{a}$ reflex } \\
\hline Gastrocnemius & 49.9 & 54.2 & -4.3 \\
\hline Lateral hamstring & 73.5 & 74.0 & -0.5 \\
\hline Medial hamstring & 73.8 & 72.4 & 1.4 \\
\hline Lateral quadriceps & 73.8 & 74.5 & -0.7 \\
\hline Medial quadriceps & 69.7 & 70.2 & -0.5 \\
\hline Predominant recruitment order & $\mathbf{G}, \mathbf{H}, \mathbf{Q}$ & $\mathrm{G}, \mathrm{H}, \mathrm{Q}$ & \\
\hline \multicolumn{4}{|l|}{ Intermediate } \\
\hline Gastrocnemius & 142.8 & 146.1 & -3.3 \\
\hline Lateral hamstring & 141.4 & 139.4 & 2.0 \\
\hline Medial hamstring & 141.1 & 139.3 & 1.8 \\
\hline Lateral quadriceps & 143.9 & 146.1 & -2.2 \\
\hline Medial quadriceps & 142.3 & 148.8 & -6.5 \\
\hline Predominant recruitment order & $\mathrm{H}, \mathrm{Q}, \mathrm{G}$ & $\mathrm{H}, \mathrm{Q}, \mathrm{G}$ & \\
\hline \multicolumn{4}{|l|}{ Voluntary } \\
\hline Gastrocnemius & 254.2 & 255.3 & -1.1 \\
\hline Lateral hamstring & 234.6 & 237.3 & -2.7 \\
\hline Medial hamstring & 226.1 & 235.7 & $-9.6^{b}$ \\
\hline Lateral quadriceps & 233.1 & 235.7 & -2.6 \\
\hline Medial quadriceps & 250.9 & 252.4 & -1.5 \\
\hline Predominant recruitment order & $\mathrm{H}, \mathbf{Q}, \mathbf{G}$ & $\mathrm{H}, \mathrm{Q}, \mathrm{G}$ & \\
\hline
\end{tabular}

a Spinal cord.

${ }^{b}$ Significant difference $(P=0.05)$.

TABLE 4

Male/female comparison of ACL-deficient and normal

\begin{tabular}{|c|c|c|c|c|c|c|}
\hline & \multicolumn{3}{|c|}{ ACL-deficient $(\%)$} & \multicolumn{3}{|c|}{ Normal_dominant leg $(\%)$} \\
\hline & Males & Females & Difference & Males & Females & Difference \\
\hline Age & 27.3 & 26.2 & 1.1 & 23.2 & 24.0 & -0.8 \\
\hline Activity level & 6.1 & 5.4 & 0.7 & 6.1 & 5.1 & 1.0 \\
\hline \multicolumn{7}{|l|}{ Strength $^{a}$} \\
\hline Quadriceps & 71.3 & 53.3 & $18.0^{b}$ & 89.6 & 80.1 & $9.5^{b}$ \\
\hline Hamstrings & 43.0 & 36.1 & 6.9 & 49.8 & 42.4 & 7.4 \\
\hline \multicolumn{7}{|l|}{ Displacement (mm) } \\
\hline Subjective eval. (total) & 64.6 & 57.6 & 7.0 & & & \\
\hline Pain & 56.7 & 51.0 & 5.7 & & & \\
\hline Swelling & 66.9 & 58.1 & 8.8 & & & \\
\hline Partial giving way & 57.1 & 50.5 & 6.6 & & & \\
\hline Full giving way & 71.3 & 64.3 & 7.0 & & & \\
\hline
\end{tabular}

${ }^{a}$ Strength $=($ Peak torque/Body weight $) \times 100 \%$.

${ }^{b}$ Significant difference at $P=0.05$ level.

Because most traditional EMG testing data are generated electrophysiologically, mechanically induced EMG muscle activity requires careful interpretation. Therefore, only those signals that were reproducible were analyzed and incorporated into the data base.

\section{Statistics}

All data were first tested for normality, and nonparametric and parametric hypothesis testing was then applied when appropriate. The analysis of data included $t$-test comparisons between dominant and nondominant lower extremities in both the normal and ACL-D groups. Comparative results between the ACL-D subgroups and the control group were statistically compared using multiway analysis of variance with Bonferroni's correction factor for repeated measures. Tukey's post hoc tests were also incorporated when appropriate. In several instances where the data violated the definition of "normality," the Friedman test (a robust, nonparametric measure) was used. In all tests, a $P$ value of less than 0.05 was considered significant.

\section{Results summary-normal controls}

1. The average ATT with muscles relaxed was $5.4 \mathrm{~mm}$ when a 30-pound anteriorly directed step force was applied to the proximal leg (Table 1).

2. Quadriceps strength averaged $86 \%$ of body weight (torque foot-pounds/body weight pounds), while the hamstrings averaged $47 \%$ (Table 1 ).

3 . The average activity level for the normal group was 5.6 (scale 0 to 10) (Table 1).

4. At the spinal cord level, the initial response to ATT was usually seen in the gastrocnemius muscle, while the ham- 
TABLE 5

Muscle timing in response to anterior tibial translation

\begin{tabular}{|c|c|c|c|}
\hline & \multicolumn{3}{|c|}{ Uninvolved extremity of ACL subject vs. normal (control) average response times (msec) } \\
\hline & $\begin{array}{l}\text { Uninvolved } \\
\text { extremity }\end{array}$ & $\begin{array}{c}\text { Normal } \\
\text { (control) }\end{array}$ & Difference \\
\hline \multicolumn{4}{|l|}{$\mathrm{SC}^{a}$ reflex } \\
\hline Gastrocnemius & 52.2 & 49.9 & 2.3 \\
\hline Lateral hamstring & 70.4 & 73.5 & -3.1 \\
\hline Medial hamstring & 69.2 & 73.8 & -4.6 \\
\hline Lateral quadriceps & 72.6 & 73.8 & -1.2 \\
\hline Medial quadriceps & 70.6 & 69.7 & 0.9 \\
\hline Predominant recruitment order & $\mathrm{G}, \mathrm{H}, \mathrm{Q}$ & $\mathrm{G}, \mathrm{H}, \mathrm{Q}$ & \\
\hline \multicolumn{4}{|l|}{ Intermediate } \\
\hline Gastrocnemius & 157.8 & 146.1 & $11.7^{b}$ \\
\hline Lateral hamstring & 146.0 & 139.4 & 6.6 \\
\hline Medial hamstring & 146.3 & 139.3 & 7.0 \\
\hline Lateral quadriceps & 145.5 & 146.1 & -0.6 \\
\hline Medial quadriceps & 144.1 & 148.8 & -4.7 \\
\hline Predominant recruitment order & $\mathrm{Q}, \mathrm{H}, \mathrm{G}$ & $\mathrm{H}, \mathrm{Q}, \mathrm{G}$ & \\
\hline \multicolumn{4}{|l|}{ Voluntary } \\
\hline Gastrocnemius & 261.8 & 255.3 & 6.5 \\
\hline Lateral hamstring & 258.1 & 237.3 & $20.8^{b}$ \\
\hline Medial hamstring & 255.9 & 235.7 & $20.2^{b}$ \\
\hline Lateral quadriceps & 260.0 & 235.7 & $24.3^{b}$ \\
\hline Medial quadriceps & 268.0 & 252.4 & $15.6^{b}$ \\
\hline Predominant recruitment order & $\mathrm{H}, \mathrm{G}, \mathrm{Q}$ & $\mathrm{H}, \mathrm{Q}, \mathrm{G}$ & \\
\hline
\end{tabular}

a Spinal cord.

${ }^{b}$ Significant difference $(P=0.05)$; leg dominance not considered.

TABLE 6

Muscle timing in response to anterior tibial translation

\begin{tabular}{|c|c|c|c|c|}
\hline & \multicolumn{4}{|c|}{ ACL subgroups vs. normal (control) average response times (msec) } \\
\hline & Normal & Acute & Semiacute & Chronic \\
\hline \multicolumn{5}{|l|}{$\mathrm{SC}^{a}$ reflex } \\
\hline Gastrocnemius & 49.9 & 51.7 & 63.4 & 55.5 \\
\hline Medial hamstring & 73.8 & $88.0^{b}$ & 82.7 & $86.8^{b}$ \\
\hline Lateral quadriceps & 73.8 & 81.7 & $94.3^{b}$ & $84.3^{b}$ \\
\hline Medial quadriceps & 69.7 & 77.8 & $84.2^{b}$ & $87.1^{b}$ \\
\hline Gastrocnemius & 142.8 & $161.3^{b}$ & $164.9^{b}$ & $167.3^{b}$ \\
\hline Lateral hamstring & 141.4 & $153.4^{b}$ & 148.9 & $153.9^{b}$ \\
\hline Medial hamstring & 141.1 & $153.0^{b}$ & 145.0 & $153.8^{b}$ \\
\hline Lateral quadriceps & 143.9 & 151.2 & 148.8 & $155.2^{b}$ \\
\hline Medial quadriceps & 142.3 & 147.3 & $151.9^{b}$ & $159.2^{b}$ \\
\hline Predominant recruitment order & $\mathrm{H}, \mathrm{Q}, \mathrm{G}$ & $\mathrm{Q}, \mathrm{H}, \mathrm{G}$ & $\mathrm{H}, \mathrm{Q}, \mathrm{G}$ & $\mathrm{H}, \mathrm{Q}, \mathrm{G}$ \\
\hline \multicolumn{5}{|l|}{ Voluntary } \\
\hline Predominant recruitment order & $\mathrm{H}, \mathrm{Q}, \mathrm{G}$ & $\mathrm{Q}, \mathrm{H}, \mathrm{G}$ & G,Q,H & $\mathrm{H}, \mathrm{Q}, \mathrm{G}$ \\
\hline
\end{tabular}

${ }^{a}$ Spinal cord.

${ }^{b}$ Significant difference $(P=0.05)$ when compared with the normal group; leg dominance not considered.

strings were most often recruited first during the intermediate and voluntary phases (Table 2).

5. There was no significant difference in the muscle recruitment order or MRT between dominant and nondominant extremities in the spinal cord reflex or intermediate response; however, during voluntary activity the medial hamstrings were statistically faster on the dominant extremity (Table 3).

6. There was no significant difference between male and female normals in terms of age, activity level, hamstrings strength, ATT, and subjective evaluation score; however, the quadriceps strength of normal men was significantly better than that of women (Table 4).

\section{Uninvolved extremities-ACL-D individuals}

1. The spinal cord response to ATT of the uninvolved extremity was not significantly different from normal (Table 5).

2. The intermediate response in the gastrocnemius 


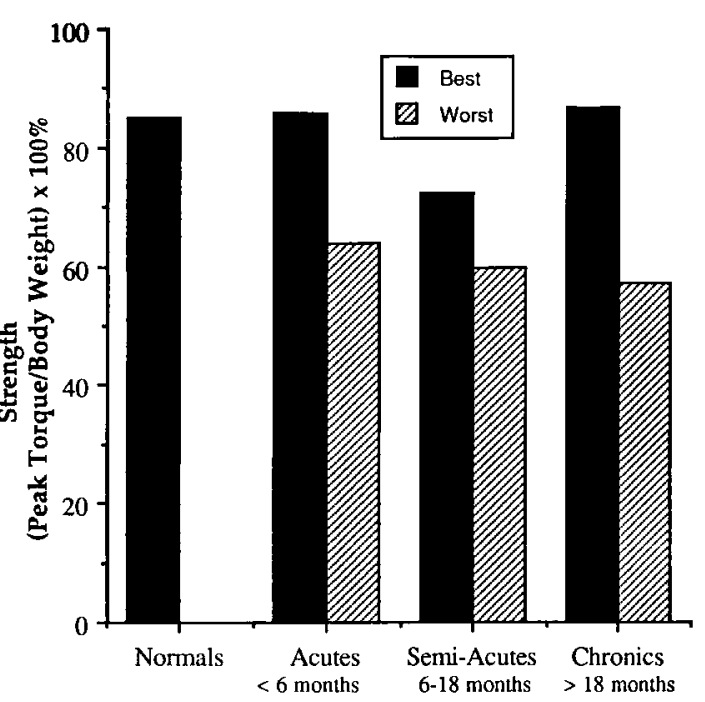

A

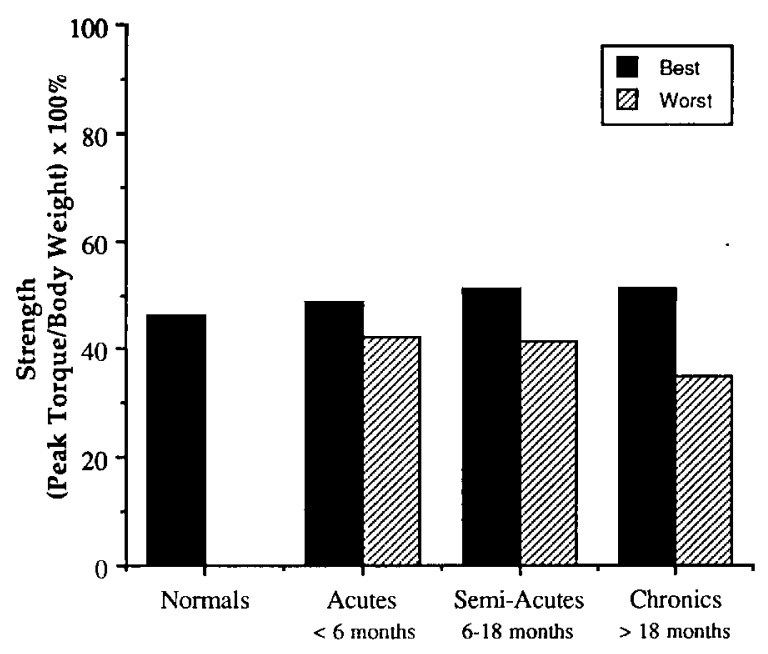

B

Figure 2. A, quadriceps muscle strength versus time from injury. $B$, hamstrings strength versus time from injury.

muscle and the voluntary activity of both medial and lateral hamstrings and quadriceps muscles were slower than normal (Table 5).

\section{ACL-D individuals}

1. There was no difference in ATT (in millimeters) between the best and worst subjectively rated ACL time groups (acute, semiacute, and chronic groups) during the muscles-relaxed test (Table 1).

2. During the muscles-tensed test, the best semiacute and chronic ACL-D extremities had significantly less ATT than the worst ACL-D extremities at those time periods (Table 1).

3. In the best ACL-D subgroups, the activity level rose from the semiacute to chronic states, while in the worst ACL-D subgroups it decreased minimally (Table 1).
4. There were no significant differences between male and female ACL-D individuals in terms of age, activity level, hamstrings strength, ATT, and subjective evaluation; only quadriceps muscle strength (corrected for body weight) was significantly better in men than women (Table 4).

5. The majority of acute ACL-D individuals used a muscle recruitment order different from normal (Table 6).

6. Most semiacute and chronic ACL-D individuals used a normal muscle recruitment order in response to ATT at the spinal cord, intermediate response, and voluntary levels (Table 6). Also, chronic ACL-D individuals used their hamstrings first to resist ATT almost twice as frequently as acute ACL-D individuals.

7. Chronic ACL-D individuals remained slower in their MRT in all five muscle groups during the intermediate response and voluntary activity when compared with normals (Table 6).

8. The quadriceps strength (peak torque foot-pounds/ body weight pounds) of normals, the best acute ACL-D individuals, and the best chronic ACL-D individuals was not statistically different (Fig. 2).

9. The hamstrings strength (peak torque foot-pounds/ body weight pounds) of the best ACL-D subgroups at each time interval was as good or better than normal, while in the worst ACL-D subgroups, the hamstrings strength was less than normal (Fig. 2).

10. The best subset of each ACL-D interval (acute, semiacute, chronic groups) favored initial use of the hamstrings to prevent ATT during voluntary activity (Table 7).

11. Those ACL-D individuals who recruited the hamstrings first during voluntary activity showed the largest decrease in laxity between their muscles-relaxed and muscles-tensed tests. Interestingly, this hamstring-first group also showed a higher average subjective score than those using their quadriceps or gastrocnemius muscles first (Table 8).

12. The ACL-D extremity showed a statistically slower MRT at the spinal cord level than the uninvolved extremity for both hamstrings and quadriceps muscles (Table 9).

13 . Voluntary muscle activity in all five muscle groups tested was slower in the ACL-D extremity than in the unaffected extremity of the individual (Table 9) and was also slower than normal (Table 10). The unaffected extremity voluntary activity was slower than normal in both hamstrings and quadriceps muscles (Table 5).

14. The dominant ACL-D extremities showed slightly more ATT and were stronger than the nondominant ACL-D extremities; these differences were not significant (Table 11).

15. Increased activity levels among the ACL-D individuals correlated well with decreased laxity in the musclestensed test (Fig. 3).

16. The ACL-D individuals who used the gastrocnemius muscle first in the intermediate response were minimally more stable during the muscles-relaxed test and were less symptomatic in terms of pain, swelling, and giving way (Table 12).

17. In ACL-D women, the intermediate medial hamstring and the voluntary gastrocnemius responses were 
TABLE 7

Muscle timing - best and worst of ACL time groups versus average muscle response times $(\mathrm{msec})^{a}$

\begin{tabular}{|c|c|c|c|c|c|c|c|}
\hline & \multirow{2}{*}{ Normal } & \multicolumn{2}{|c|}{ Chronic } & \multicolumn{2}{|c|}{ Semiacute } & \multicolumn{2}{|c|}{ Acute } \\
\hline & & Best & Worst & Best & Worst & Best & Worst \\
\hline \multicolumn{8}{|l|}{ Spinal cord reflex } \\
\hline Gastrocnemius & 49.9 & 49.8 & 46.0 & 63.8 & 74.5 & 31.5 & 47.0 \\
\hline Lateral hamstring & 73.5 & 82.6 & 85.1 & 77.0 & $95.4^{b}$ & 83.6 & $110.5^{c}$ \\
\hline Medial hamstring & 73.8 & $87.4^{b}$ & $88.3^{b}$ & 79.0 & $97.8^{b}$ & 75.4 & 80.0 \\
\hline Lateral quadriceps & 73.8 & 78.1 & 83.7 & 89.5 & $106.0^{b}$ & $46.0^{c}$ & $103.7^{c}$ \\
\hline Medial quadriceps & 69.7 & 78.5 & $104.0^{c}$ & 81.0 & 85.0 & 66.2 & $89.5^{c}$ \\
\hline \multicolumn{8}{|l|}{ Intermediate } \\
\hline Gastrocnemius & 142.8 & 161.1 & $187.8^{c}$ & 145.4 & $186.0^{\circ}$ & 129.6 & 148.0 \\
\hline Lateral hamstring & 141.4 & 133.0 & $176.6^{c}$ & 149.0 & 151.6 & 135.6 & $160.6^{c}$ \\
\hline Medial hamstring & 141.4 & 135.0 & $185.1^{c}$ & 146.6 & 148.2 & 136.6 & $155.6^{b}$ \\
\hline Lateral quadriceps & 143.9 & 136.9 & $187.8^{c}$ & 139.0 & $169.8^{c}$ & 141.4 & $169.8^{c}$ \\
\hline Medial quadriceps & 142.9 & 145.8 & $198.3^{c}$ & 147.2 & 154.8 & 134.6 & $162.5^{c}$ \\
\hline Predom. rec. order & $\mathrm{H}, \mathrm{Q}, \mathrm{G}$ & $\mathrm{H}, \mathrm{Q}, \mathrm{G}$ & None & $\mathrm{G}, \mathrm{H}, \mathrm{Q}$ & $\mathrm{H}, \mathrm{Q}, \mathrm{G}$ & $\mathrm{Q}, \mathrm{H}, \mathrm{G}$ & $\mathrm{Q}, \mathrm{H}$ \\
\hline \multicolumn{8}{|l|}{ Voluntary } \\
\hline Gastrocnemius & 254.2 & 274.4 & $296.2^{b}$ & $326.8^{b}$ & $291.0^{b}$ & $284.3^{b}$ & $361.3^{c}$ \\
\hline Lateral hamstring & 234.6 & 259.4 & $340.0^{c}$ & $269.4^{b}$ & $314.2^{c}$ & 264.2 & $344.6^{c}$ \\
\hline Medial hamstring & 226.1 & $255.4^{b}$ & $354.5^{c}$ & $278.2^{b}$ & $295.8^{b}$ & $263.6^{b}$ & $360.8^{c}$ \\
\hline Lateral quadriceps & 233.1 & $268.4^{b}$ & $299.1^{c}$ & $279.4^{b}$ & $298.3^{b}$ & $299.8^{b}$ & $327.4^{b}$ \\
\hline Medial quadriceps & 250.9 & 282.6 & $317.7^{c}$ & $293.3^{b}$ & $291.2^{b}$ & 281.4 & $318.8^{b}$ \\
\hline Predom. rec. order & $\mathrm{H}, \mathrm{Q}, \mathrm{G}$ & $\mathbf{H}, \mathbf{Q}, \mathrm{G}$ & $\mathrm{Q}, \mathrm{G}, \mathrm{H}$ & $\mathrm{H}, \mathrm{Q}, \mathrm{G}$ & $\mathrm{Q}, \mathrm{H}, \mathrm{G}$ & $\mathrm{H}, \mathrm{Q}, \mathrm{G}$ & $\mathrm{Q}, \mathrm{H}, \mathrm{G}$ \\
\hline
\end{tabular}

${ }^{a}$ Significant at $P=0.05$ level; best in terms of subjective evaluation compared with worst in each subgroup.

${ }^{b}$ Significant with the normal control group only.

c Significant with both groups 1) best versus worst, and 2) normal control groups.

TABLE 8

ACL-deficient subjects - voluntary activity analysis of initial muscle recruitment versus anterior tibial displacement, strength, activity level, and subjective evaluation

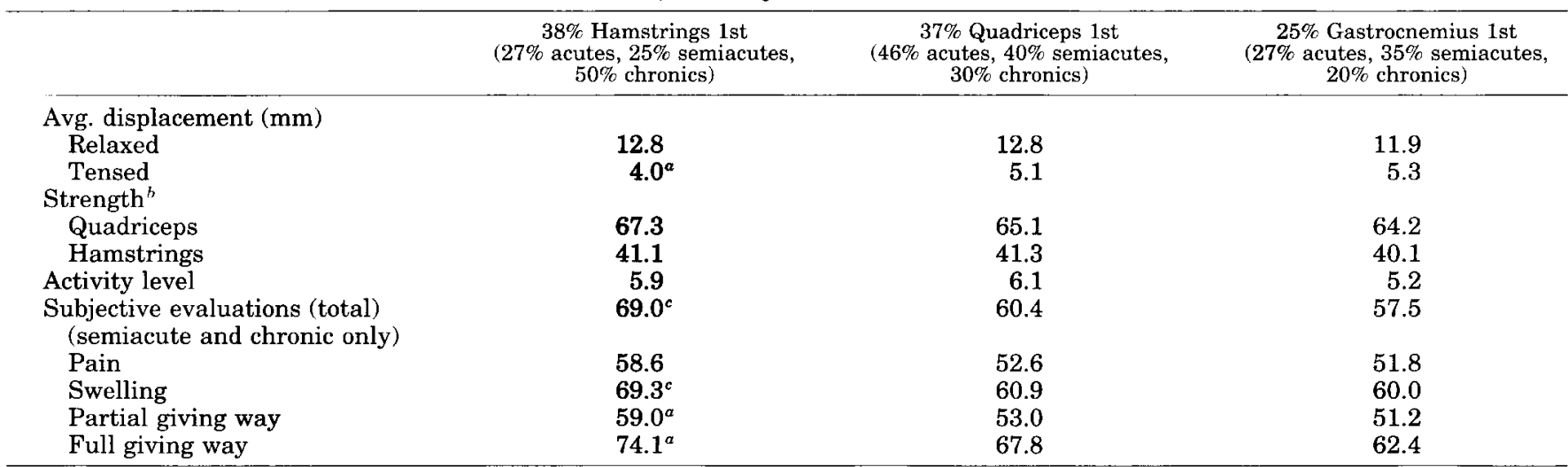

${ }^{a}$ Significant with gastrocnemius only.

${ }^{b}$ Strength $=($ Peak torque/Body weight $) \times 100 \%$.

: Significant with both groups.

significantly slower than in ACL-D men. Women with normal extremities demonstrated faster intermediate lateral quadriceps and voluntary medial hamstring response than did men with normal extremities (Table 13).

\section{DISCUSSION}

Dynamic protection of the knee joint during injuryproducing activities requires the recognition of the dangerous force through peripheral or central receptors, afferent transmission to either the spinal cord or higher centers in the CNS, processing of the signal, and then an appropriate response. Beard et al. ${ }^{8}$ defined these proprioceptive abilities in terms of static awareness of joint position in space, kinesthetic awareness (detection of limb movement and acceleration), and closed-loop efferent activity that is required for a reflex response and the regulation of muscle stiffness. The speed of a protective response is determined by the site of the afferent reception (central versus peripheral site) and the location of the signal-processing center (spinal cord versus cerebral cortex). The location of the afferent signal processing center (spinal cord versus cortex) is important because it determines the distance a signal must travel to generate an efferent response. Visual afferent input to the cortex can produce a more timely voluntary response than peripheral afferent input because an injury-producing situation may be recognized in advance; peripheral mechanoreceptors cannot begin their afferent signal until the onset of the injury-producing force. While cortical recognition may be 
TABLE 9

Muscle timing in response to anterior tibial translation

\begin{tabular}{|c|c|c|c|}
\hline & \multicolumn{3}{|c|}{ ACL-deficient involved vs. uninvolved extremity average response times (msec) } \\
\hline & Involved & Uninvolved & Difference \\
\hline \multicolumn{4}{|l|}{$\mathrm{SC}^{a}$ reflex } \\
\hline Gastrocnemius & 56.1 & 52.2 & 3.9 \\
\hline Medial hamstring & 86.4 & 69.2 & $17.2^{b}$ \\
\hline Lateral quadriceps & 85.7 & 72.6 & $13.1^{b}$ \\
\hline Medial quadriceps & 83.6 & 70.6 & $13.0^{b}$ \\
\hline Gastrocnemius & 165.0 & 157.8 & 7.2 \\
\hline Lateral hamstring & 152.8 & 146.0 & 6.8 \\
\hline Medial hamstring & 151.8 & 146.3 & 5.5 \\
\hline Lateral quadriceps & 152.7 & 145.5 & 7.2 \\
\hline Medial quadriceps & 154.2 & 144.1 & $10.1^{b}$ \\
\hline Predominant recruitment order & $\mathrm{H}, \mathrm{Q}, \mathrm{G}$ & $\mathbf{Q}, \mathrm{H}, \mathbf{G}$ & \\
\hline \multicolumn{4}{|l|}{ Voluntary } \\
\hline Predominant recruitment order & $\mathrm{H}, \mathrm{Q}, \mathrm{G}$ & $\mathrm{H}, \mathrm{G}, \mathrm{Q}$ & \\
\hline
\end{tabular}

${ }^{a}$ Spinal cord.

${ }^{b}$ Significant difference $(P=0.05)$; leg dominance not considered.

TABLE 10

Muscle timing in response to anterior tibial translation

\begin{tabular}{|c|c|c|c|}
\hline & \multicolumn{3}{|c|}{ ACL-deficient extremity vs. normal (control) average response times (msec) } \\
\hline & ACL-deficient & Normal group dominant leg & Difference \\
\hline \multicolumn{4}{|l|}{$\mathrm{SC}^{a}$ reflex } \\
\hline Gastrocnemius & 56.1 & 49.9 & 6.2 \\
\hline Medial hamstring & 86.4 & 73.8 & $12.6^{b}$ \\
\hline Lateral quadriceps & 85.7 & 73.8 & $11.9^{b}$ \\
\hline Medial quadriceps & 83.6 & 69.7 & $13.9^{b}$ \\
\hline Gastrocnemius & 165.0 & 146.1 & $9.0^{c}$ \\
\hline Lateral hamstring & 152.8 & 139.4 & $11.1^{c}$ \\
\hline Medial hamstring & 151.8 & 139.3 & $10.7^{c}$ \\
\hline Lateral quadriceps & 152.7 & 146.1 & 6.6 \\
\hline Medial quadriceps & 154.2 & 148.8 & 5.4 \\
\hline Predominant recruitment order & $\mathrm{H}, \mathrm{Q}, \mathrm{G}$ & $\mathrm{H}, \mathrm{Q}, \mathrm{G}$ & \\
\hline \multicolumn{4}{|l|}{ Voluntary } \\
\hline Medial quadriceps & 290.2 & 252.4 & $19.8^{\mathrm{c}}$ \\
\hline Predominant recruitment order & $\mathrm{H}, \mathrm{Q}, \mathrm{G}$ & $\mathrm{H}, \mathrm{Q}, \mathrm{G}$ & \\
\hline
\end{tabular}

a Spinal cord.

${ }^{b}$ Significant difference $(P=0.05)$; leg dominance not considered.

${ }^{c}$ Significant difference $(P=0.05)$; leg dominance considered.

advantageous in many situations, local stimuli at the spinal cord level may prove to be adequate to generate a protective muscle response. This dynamic local response may not generate any limb movement. In fact, a generalized limb stiffening through muscle cocontraction may be all that is needed to prevent knee joint injury.

Purposeful muscle activity can be classified as automatic, semiautomatic, or voluntary, depending on the level of cortical involvement. ${ }^{28}$ Automatic or reflex responses originating at the spinal cord are usually generated by local stimuli and can be characterized as gross, quick movements that require no cortical input or sensory feedback. Semiautomatic movement (rhythmic behavior) usually requires supraspinal initiation and termination but proceeds automatically in terms of neural control (i.e., chewing, walking). These semiautomatic motions are intermediates between reflex and voluntary activity. They are controlled by neural networks in the spinal cord and brain stem. ${ }^{28}$ 
TABLE 11

ACL-deficient extremities-dominant versus nondominant

\begin{tabular}{|c|c|c|c|}
\hline & Dominant & Nondominant & Difference \\
\hline \multicolumn{4}{|l|}{ Strength $^{a}$} \\
\hline Hamstrings & 45.8 & 40.9 & 4.9 \\
\hline \multicolumn{4}{|l|}{ Displacement $(\mathrm{mm})$} \\
\hline Muscles tensed & 6.1 & 4.6 & 1.5 \\
\hline Muscles relaxed & 11.1 & 9.3 & 1.8 \\
\hline \multicolumn{4}{|l|}{$\mathrm{SC}^{b}$ reflex } \\
\hline Gastrocnemius & 57.8 & 54.3 & 3.5 \\
\hline Lateral hamstring & 80.7 & 82.3 & -1.6 \\
\hline Medial hamstring & 82.7 & 89.7 & -7.0 \\
\hline Lateral quadriceps & 84.7 & 86.7 & -2.0 \\
\hline Medial quadriceps & 80.1 & 86.9 & -6.8 \\
\hline \multicolumn{4}{|l|}{ Intermediate } \\
\hline Medial quadriceps & 158.2 & 154.9 & 3.3 \\
\hline \multicolumn{4}{|l|}{ Voluntary } \\
\hline Gastrocnemius & 285.3 & 282.9 & 2.4 \\
\hline Lateral hamstring & 288.9 & 287.6 & 1.3 \\
\hline Medial hamstring & 289.3 & 280.9 & 8.4 \\
\hline Lateral quadriceps & 278.7 & 296.9 & $-18.2^{c}$ \\
\hline Medial quadriceps & 289.6 & 307.6 & $-18.0^{c}$ \\
\hline
\end{tabular}

${ }^{a}$ Strength $=($ Peak torque/Body weight $) \times 100 \%$.

${ }^{b}$ Spinal cord.

${ }^{c}$ Significant at the $P=0.05$ level.

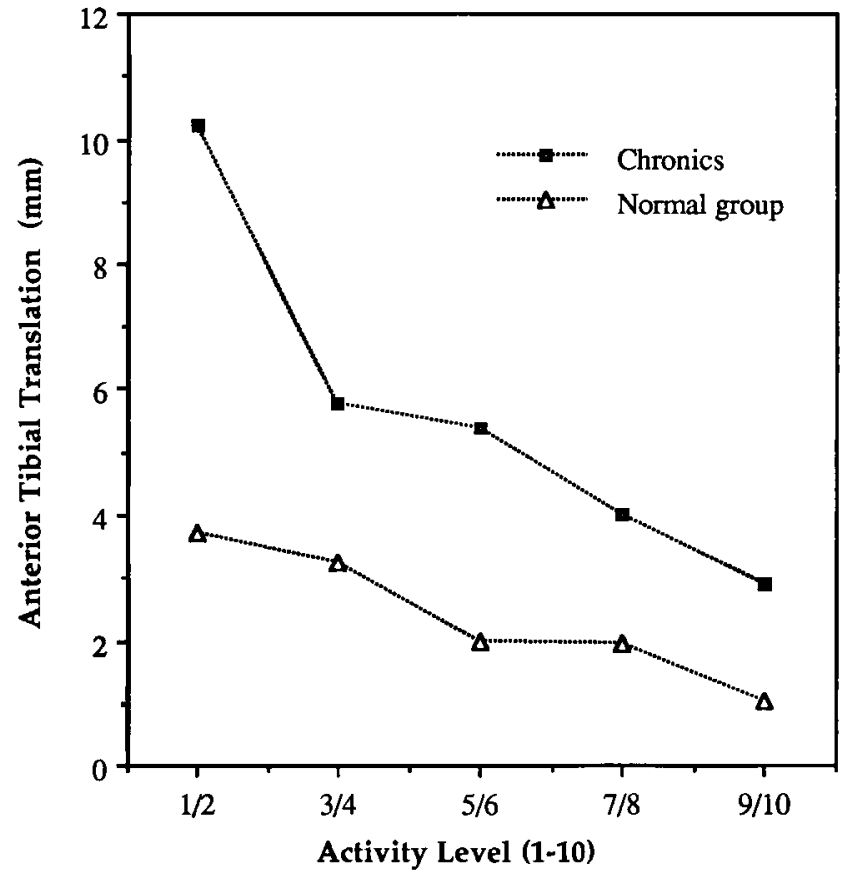

Figure 3. Activity level versus knee laxity with muscles tensed. Activity levels 0 through 10 are defined in Table 1.

These neural networks are "pattern generators," composed of reciprocal connections between pools of neurons waiting to be triggered. ${ }^{28}$
Voluntary movements, which have the most cortical control, are affected by attention and motivation. They are learned and require practice for perfection. Once learned, complicated voluntary movements can be used to form a motor program by which complex tasks are accomplished without thinking about each step (i.e., typing). The amount of conscious effort needed to accomplish a task is an important determinant of the speed at which it can be accomplished.

The speed of limb movement is an important factor in many athletic activities. Several studies have focused on the level of neuromuscular activity during rigorous sports, such as skiing, and have asked this question: "Can muscles react fast enough to offer protection to the static restraints of the knee joint?"5,21,55 Ligament injuries can occur in a fraction of a second. Yasuda et al ${ }^{84}$ recently reported that peak strains occur in the ACL at 40 to $70 \mathrm{msec}$ after the application of a damaging valgus force to the knee. Consequently, most investigators would agree that a voluntary response to a damaging force is too slow to protect ligaments. ${ }^{28}$ More specifically, Pope et al. ${ }^{65}$ concluded that a musculoprotective reflex initiated by pain or tendon stretch could not be quick enough to protect knee ligaments from injury. However, this work did not take into account the anticipation of the damaging force, allowing activation of a voluntary response before the injury-producing event. If the injury situation can be anticipated and a coordinated muscle response formulated before the peak strain produced by a damaging force, adequate voluntary protection may be available to the static restraints of the knee. In the 
TABLE 12

ACL-deficient subjects intermediate analysis-initial muscle recruitment versus anterior tibial displacement, strength, activity level, and subjective evaluation

\begin{tabular}{|c|c|c|c|}
\hline & $\begin{array}{c}52 \% \text { Hamstrings 1st } \\
(30 \% \text { acutes, } 65 \% \text { semiacutes, } \\
61 \% \text { chronics })\end{array}$ & $\begin{array}{c}37 \% \text { Quadriceps } 1 \text { st } \\
(55 \% \text { acutes, } 20 \% \text { semiacutes, } \\
33 \% \text { chronics) }\end{array}$ & $\begin{array}{c}11 \% \text { Gastrocnemius } 1 \text { st } \\
\text { (15\% acutes, } 15 \% \text { semiacutes, } \\
6 \% \text { chronics) }\end{array}$ \\
\hline \multicolumn{4}{|l|}{ Avg. displacement (mm) } \\
\hline Relaxed & 13.0 & $12.4^{a}$ & $11.2^{b}$ \\
\hline Tensed & 5.2 & 5.2 & 5.0 \\
\hline \multicolumn{4}{|l|}{ Strength $^{c}$} \\
\hline Quadriceps & 67.8 & 65.1 & 58.6 \\
\hline Hamstrings & 41.9 & 40.0 & 39.6 \\
\hline Activity level & 5.7 & 6.0 & 5.8 \\
\hline $\begin{array}{l}\text { Subjective evaluations (total) } \\
\text { (semiacute and chronic only) }\end{array}$ & 61.3 & 63.7 & $71.3^{a}$ \\
\hline Pain & 53.5 & 56.8 & 58.3 \\
\hline Swelling & 62.1 & 66.8 & $73.3^{a}$ \\
\hline Partial giving way & 54.2 & 54.2 & $65.0^{b}$ \\
\hline Full giving way & 68.4 & 68.4 & $80.0^{b}$ \\
\hline
\end{tabular}

${ }^{a}$ Significant with hamstring only.

${ }^{b}$ Significant with both groups.

${ }^{\mathrm{c}}$ Strength $=($ Peak torque $/$ Body weight $) \times 100 \%$.

TABLE 13

Muscle timing in response to anterior tibial translation gender comparison-ACL-deficient and normal patients' average response times (msec)

\begin{tabular}{|c|c|c|c|c|c|c|}
\hline & \multicolumn{3}{|c|}{ ACL-deficient } & \multicolumn{3}{|c|}{ Normal } \\
\hline & Males & Females & Difference & Males & Females & Difference \\
\hline \multicolumn{7}{|l|}{$\mathrm{SC}^{a}$ reflex } \\
\hline Gastrocnemius & 57.3 & 53.4 & 3.9 & 54.4 & 53.9 & 0.5 \\
\hline Lateral hamstring & 79.5 & 85.5 & -6.0 & 77.2 & 70.4 & 6.8 \\
\hline Medial hamstring & 85.0 & 894 & -4.4 & 73.4 & 71.4 & 2.0 \\
\hline Lateral quadriceps & 84.0 & 80.8 & -4.9 & 77.0 & 71.0 & 6.0 \\
\hline Medial quadriceps & 81.8 & 87.1 & -5.3 & 73.8 & 66.3 & 7.5 \\
\hline \multicolumn{7}{|l|}{ Intermediate } \\
\hline Gastrocnemius & 166.3 & 162.8 & 3.5 & 145.9 & 138.3 & 7.6 \\
\hline Lateral hamstring & 150.4 & 157.9 & -7.5 & 143.7 & 137.4 & 6.3 \\
\hline Medial hamstring & 148.6 & 158.5 & $-9.9^{b}$ & 142.2 & 138.9 & 3.3 \\
\hline Lateral quadriceps & 150.6 & 156.9 & -6.3 & 147.4 & 137.2 & $10.2^{b}$ \\
\hline Medial quadriceps & 151.8 & 158.9 & -7.1 & 142.3 & 142.3 & 0.0 \\
\hline \multicolumn{7}{|l|}{ Voluntary } \\
\hline Gastrocnemius & 282.2 & 301.1 & $-18.9^{b}$ & 252.2 & 246.9 & 5.3 \\
\hline Lateral hamstring & 296.0 & 292.9 & 3.1 & 233.0 & 228.8 & 4.2 \\
\hline Medial hamstring & 288.4 & 294.7 & -6.3 & 233.1 & 211.0 & $22.1^{6}$ \\
\hline Lateral quadriceps & 286.5 & 286.6 & -0.1 & 229.5 & 223.9 & 5.6 \\
\hline Medial quadriceps & 293.9 & 289.6 & 4.3 & 253.8 & 253.7 & 0.1 \\
\hline
\end{tabular}

${ }^{a}$ Spinal cord.

${ }^{b}$ Significant difference at $P=0.05$ level.

event that injury anticipation is not possible, fortunately, spinal cord reflexes require less time than voluntary activity. In fact, spinal cord level responses may occur fast enough to provide gross protection to the knee joint (Table 3 , SC reflex), and they may play an even greater protective role by provoking a muscle pattern generator. ${ }^{28}$ Intrinsic receptors of muscles can activate tonic stretch reflexes in the gamma innervation system of muscle. Gamma activation can set the muscle spindle at a more active level, thereby reflexively increasing muscle control. ${ }^{48,60,67}$ This heightened sensitivity may play an even greater role after an ACL tear because of the reported decline in proprioception. ${ }^{6}$

The MRTs recorded in the three regions of the EMG recording (spinal cord reflex, intermediate response, and voluntary activity) constitute a large ingredient of this paper.
Yet it is fair to say that we can only speculate on the significance of these changes in MRT. However, since Yasuda et al. ${ }^{84}$ reported peak strains occurring in an ACL injury experiment as early as $40 \mathrm{msec}$ after the application of a valgus force, it seems reasonable that differences in MRT of this magnitude should be considered until better indicators of significance are available.

While it may seem difficult to believe that a 20 - to 40 msec delay in MRT might be a factor in knee joint protection, no actual joint motion may be needed to prevent injury. In fact, the split-second activation of the muscles crossing the knee joint may only be needed to stiffen the extremity to resist deforming forces.

In the event of an ACL injury, there is evidence suggesting that the CNS can adjust and reprogram with time to protect the unstable joint. O'Connor et al. ${ }^{58}$ reported the 
effects of dorsal root ganglionectomy before, and 52 weeks after, sectioning of the ACL in dogs. The group of dogs that experienced 52 weeks of CNS reconditioning after sectioning of the ACL before the dorsal root ganglionectomy did much better during gait analysis and in the prevention of osteoarthritic degeneration with time.

\section{Normal extremities}

The spinal cord reflex generated in response to ATT was usually seen first in the gastrocnemius muscle (Table 2). This was somewhat a surprise to the investigators since the hamstrings and the quadriceps muscles are usually considered the primary muscle stabilizers of the knee. In this investigation, the gastrocnemius muscle appears to play an even greater role in ACL-D extremities. It had been identified as a primary knee stabilizer in a previous gait study of ACL-D knees. ${ }^{45}$

Intermediate and voluntary response to ATT usually favored the initial use of the hamstrings (Table 2). There was very little difference in MRT between the dominant and nondominant extremities at the spinal cord and cortical levels except for the voluntary activity of the medial hamstrings; this was statistically faster on the dominant extremity (Table 3 ).

In normal extremities, the degree of ATT during the muscles-tensed test correlated statistically with the individual's lifestyle: the more active the individual, the tighter the knee. Those participating in competitive, jumping, twisting sports (high-activity level) demonstrated the least ATT (Fig. 3).

\section{Uninvolved extremities-ACL-D individuals}

A normal pattern of muscle recruitment and timing was seen at the spinal cord level in response to ATT (Table 5); however, when cortical level EMG activity was examined, differences began to appear. The intermediate response of the gastrocnemius muscle was significantly slower when compared with normal response, while the voluntary response in both the hamstrings and quadriceps muscles was also significantly slower. A quadriceps-hamstringsgastrocnemius recruitment pattern was favored in intermediate response, while normals preferred initial use of the hamstrings. The voluntary response favored the initial use of the hamstrings (Table 5), which was similar to the normal responses. Interestingly, the voluntary recruitment of both the hamstrings and quadriceps muscles in these uninvolved extremities was slower than normal.

The slowing of the MRT in the uninvolved extremity was unexpected but can be explained in several ways. One possibility is that the decreased activity of the ACL-D individuals as a group affects the normal conditioning of these protective responses, thus producing slower MRTs in their uninvolved extremities. More importantly, the initial use of the quadriceps muscle in the intermediate response may be suggestive of a more profound problem: a quadricepsdependent extremity. Since the quadriceps muscle is an ACL antagonist muscle, its initial recruitment in the intermediate response may actually represent a risk factor for ACL injury and may not represent a postinjury alteration in muscle recruitment order. Preseason testing of several athletic groups at risk for ACL injury may resolve this question.

\section{ACL-D extremities}

Intermediate response activity apparently undergoes a dramatic shift during the 18 months after an ACL tear. Acute injuries (less than 6 months from injury) favor the initial use of the quadriceps muscle (55\% quadriceps and $30 \%$ hamstrings), while the semiacute ACL tears ( 6 to 18 months postinjury) shift over to the hamstrings ( $65 \%$ hamstrings and $20 \%$ quadriceps muscle) (Table 2). This pattern of hamstring substitution in ACL-D individuals has been reported in walking, stair climbing, and more stressful activities. ${ }^{39,83}$ These findings also agree with EMG work by Branch et al. ${ }^{11}$ that showed decreased activity of the ACL antagonist muscle (quadriceps) and increased activity of the ACL agonist muscle (hamstrings) in the gait cycle of the ACL-D individuals an average of 66.5 months after injury.

Regardless of the time from injury, ACL-D individuals as a group usually showed spinal cord and cortical level responses to ATT slower than normal and slower than the uninvolved extremity (Tables 9 and 10). We do not know whether this pattern of generalized MRT slowing is peculiar to ACL injury or reflective of knee trauma in general.

Other investigators have indicated that loss of the ACL can result in a slower MRT. Beard et al. ${ }^{8}$ studied the latency of the hamstring reflex in 30 individuals with a unilateral ACL injury and in 20 normal individuals. The mean latency in the injured extremity was almost twice that in the uninjured extremity (99 msec versus $53 \mathrm{msec}$ ). In the normal patients, the mean interlimb differential in ATT was $4.2 \mathrm{~mm}$, and the average reflex hamstring latency was 43.2 msec. Twenty-nine of the 30 ACL-D individuals demonstrated an increase in reflex hamstring contraction latency with a mean noninjured-injured latency differential of $46.4 \mathrm{msec}$. Beard et al. reported a significant correlation between the hamstrings reflex latency and the frequency of giving-way episodes, and they suggested that a relative increase in reflex hamstring contraction latency is a measure of proprioception and can be used to provide objective data for decision-making for ACL-D individuals. Interestingly, the reflex response to passive tibial movement was reported to be significantly slower in a recently injured ACL-D extremity than in the contralateral extremity or a normal extremity.

In this investigation, the generalized MRT slowing in ACL-D individuals is most impressive at the voluntary level in the best subjectively rated, chronic ACL subgroup (Table 7). This group averaged a knee rating score of 91 on a scale of 100 (Table 1) and represents primarily highly competitive intercollegiate athletes. These individuals have the advantage of year-round, intense, sophisticated training. If these athletes cannot return their MRTs to normal 18 months after injury, it seems either that the training and conditioning of the athlete need alteration to better address deficits in MRT, or that the goal of normal MRT is unattainable after ACL injury. If the afferent arm of the 
protective reflex system has truly been damaged, as some have suggested, ${ }^{32,73}$ then normal neuromuscular function may not be achievable. Further investigation of training techniques after ACL injury may answer this question.

Muscle recruitment patterns in response to ATT appear to change with time from injury. Acutely injured ACL-D extremities initiate their intermediate and voluntary response most often in the antagonist quadriceps muscles, while normals favor the agonist hamstrings (Table 6). This seemingly unwanted quadriceps response may be the result of postinjury dysfunction caused by the loss of protective afferent input previously originating in the ACL. ${ }^{32,39,41,71-73}$

Lorentzon et al ${ }^{47}$ documented profound quadriceps dysfunction in chronic ACL-D individuals that was caused by "nonoptimal quadriceps activation" during voluntary activity secondary to impaired afferent input. There is no doubt that body movement control is dependent on feedback from peripheral receptors and the existence of learned, pattern behavior. If there is a defect in afferent input system to the CNS, or if a recent injury necessitates a pattern of integrated muscle response that has not been used previously, then muscle control could be diminished or ineffective. ${ }^{35}$ Since semiacute and chronic ACL-D extremities favor initial intermediate and voluntary response in the hamstrings (Table 6), there may be a learnable but slower compensatory mechanism that uses secondary afferent receptors other than those in the ACL.

The work of Solomonow et al. ${ }^{73}$ on the synergistic action of the ACL and thigh muscles concluded that there is a primary, fast-to-respond reflex arc from the mechanoreceptors in the normal ACL to the hamstrings. Furthermore, Solomonow et al. reported that when this arc is interrupted by an ACL injury, a secondary, slower reflex arc, originating from mechanoreceptors in muscle and joint capsule, takes control and inhibits the quadriceps muscles. These findings are in agreement with Birac et al. ${ }^{10}$ and Berchuck et al. ${ }^{9}$ who, through EMG studies, characterized the ACL-D gait pattern by its quadriceps avoidance. Also, Andriacchi et al. ${ }^{4}$ reported increases in hip flexion in ACL-D extremities during a sidestep cutting maneuver. Increased hip and knee flexion (approximately $90^{\circ}$ ) would put the hamstrings in a better position to stabilize the ACL-D extremity. All of these findings are supported by the work of Basmajian ${ }^{7}$ who showed that men can be trained to alter muscle recruitment order with proper training using biofeedback.

The role of the secondary stabilizers of the knee, including the menisci, should not be overlooked when analyzing the use of a particular muscle recruitment pattern. The role of these secondary structures in generating afferent input for protective muscle activity remains under investigation. Variables other than those investigated in this study may improve our understanding of the muscle recruitment patterns reported here.

When the members of each ACL time group were ranked on the basis of their total subjective functional score, a best and worst subgroup could be identified (Table 1). A higher subjective functional rating correlated well with better hamstrings and quadriceps strength and a higher activity level. The ATT in the muscles-tensed test was significantly less in the best subgroup of the semiacute and chronic ACL-D extremities. This ATT control correlates with the higher muscle strength (Table 1) and faster MRT (Table 7) seen in these "best" subgroups. However, the apparent lack of knee motion produced by these initial muscle responses may indicate that the MRT is not as important as the ability to coordinate the nearly simultaneous activation (cocontraction) of antagonist muscles to stiffen the knee. This possibility is currently being investigated.

The best ACL-D individuals in terms of their total subjective functional score favored the same voluntary recruitment order as most normals-hamstrings-quadricepsgastrocnemius muscles (Table 7)—while the worst ACL subgroup at each time interval (acute, semiacute, and chronic intervals) favored their ACL antagonist quadriceps muscle first in their voluntary response. Also, hamstrings and quadriceps strength in the best chronic groups was as good as or better than in the normal group (Table 1). The degree of ATT in the muscles-relaxed test did not appear to affect the subjective outcome. In fact, ATT in the muscles-relaxed test showed no significant difference between the best and the worst of each ACL-D time interval. Interestingly, in the muscles-tensed test, ATT was significantly less in the semiacute and chronic groups, suggesting that the active ability to stabilize the knee is somewhat dependent on time from injury (Table 1).

The muscle recruitment order in response to ATT may be partially dependent on the integrity of the secondary restraints in terms of their mechanical characteristics and afferent input. Grigg and Greenspan ${ }^{34}$ showed that joint afferents act as capsular stretch receptors with the level of input frequently proportional to the muscle torque generated. These studies implied that the afferent input is related to the function of the tissues to which it is associated. Those ACL-D individuals who responded first with their gastrocnemius muscle ( 70 men and 30 women) during the intermediate response (intermediate response, Table 13) showed statistically the least ATT in the muscles-relaxed test. The significance of these findings remains unclear.

There were gender differences noted in both the subjective and objective evaluations (Tables 4 and 13). The most impressive difference is the greater quadriceps strength of men even when corrected for body weight (normals, $18.0 \%$; ACL-D, 9.5\%). Unfortunately, these differences do not easily explain the epidemic of ACL injuries recently reported in women. ${ }^{49}$

Hamstring rehabilitation has been recognized as an integral factor in the recovery from ACL injury and from surgery for some time. Unfortunately, excellent hamstrings and quadriceps strength alone is obviously not enough. ${ }^{74}$ This shortcoming may be explained by the work of Barrack et al. ${ }^{6}$ that showed that the decline in proprioceptive ability of an ACL-D extremity does not correlate with strength loss, lending support to the belief that proprioceptive loss was the cause of, rather than the result of, ACL injury.

Despite all the technical improvements in our treatment of a torn $\mathrm{ACL}$ in the last 20 years, the challenge remains: to return an ACL-D or reconstructed extremity to a normal pattern of function. To accomplish this goal, rehabilitation 
and training must focus on more than muscle strengthening. Muscle timing, coordination, and integration need to be addressed.

\section{CONCLUSIONS}

1. Significant differences exist between normal and ACL-D lower extremities in terms of muscle recruitment order at the spinal cord and cortical level in response to an ATT.

2. The timing of many muscle responses to an ATT in ACL-D extremities is delayed.

3. In ACL-D extremities, both muscle timing and recruitment order change with time from injury.

4. Muscle timing and recruitment order in the ACL-D extremity directly affect the individual's physical activity level, subjective functional performance, and dynamic ATT.

\section{REFERENCES}

1. Abbott LC, Saunders JB, Bost FC, et al: Injuries to the ligaments of the knee joint. J Bone Joint Surg 26: 503-521, 1944

2. Andersson $S$, Stener B: Experimental evaluation of the hypothesis of ligamento-muscular protective reflexes. If. A study in cats using the medial collateral ligament of the knee joint. Acta Physiol Scand 48(Supp/ 166): 27-49, 1959

3. Andrew B: The sensory innervation of the medial ligament of the knee joint. J Physiol 123: 241-250, 1954

4. Andriacchi TP, Kramer GM, Landon GC: The biomechanics of running and knee injuries, in Finerman G (ed): The AAOS, Symposium on Sports Medicine. The Knee. St Louis, CV Mosby Co, 1985, pp 23-32

5. Bahniuk E, MacLaughlin TL, Van Der Meulen JP, et al: EMG response of the lower extremities to the patellar tendon tap. Am Soc Mechan Engineers 73-WA'Bio 30: 2-7, 1973

6. Barrack RL, Skinner HB, Buckley SL: Proprioception in the anterior cruciate deficient knee. Am J Sports Med 17: 1-6, 1989

7. Basmajian JV: Control and training of individual motor units. Science 141: $440-441,1963$

8. Beard DJ, Kyberd PJ, Fergusson CM, et al: Proprioception after rupture of the anterior cruciate ligament: An objective indication of the need for surgery. J Bone Joint Surg 75B: 311-315, 1993

9. Berchuck M, Andriacchi TP, Bach BR, et al: Functional adaptation in ACLdeficient patients. Trans Orthop Res Soc 13: 84, 1988

10. Birac DA, Andriacchi TP, Bach BR: Time related changes following ACL rupture. Trans Orthop Res Soc 16: 231, 1991

11. Branch TP, Hunter R, Donath M: Dynamic EMG analysis of anterior cruciate deficient legs with and without bracing during cutting. Am J Sports Med 17: 35-41, 1989

12. Brand RA: Knee ligaments: A new view. Trans Am Soc Mechan Engineers 108: $106-110,1986$

13. Brantigan OC, Voshell AF: The mechanics of the ligaments and menisci of the knee joint. J Bone Joint Surg 23: 44-66, 1941

14. Butler DL: Anterior cruciate ligament: Its normal response and replacement. J Orthop Res 7: 910-921, 1989

15. Butler DL, Noyes FR, Grood ES: Ligamentous restraints to anteriorposterior drawer in the human knee: A biomechanical study. $J$ Bone Joint Surg 62A: $259-270,1980$

16. Clancy WG, Nelson DA, Reider B, et al: Anterior cruciate ligament reconstruction using one-third of the patellar ligament, augmented by extraarticular tendon transfers. J Bone Joint Surg 64A: 352-359, 1982

17. Clark F: Information signaled by sensory fibers in medial articular nerve. $J$ Neurophysiol 38: 1464-1475, 1975

18. Cohen LA, Cohen ML: Arthrokinetic reflex of the knee. Am J Physiol 184: 433-437, 1956

19. Deschuytere $\mathrm{J}$, DeKeyser $\mathrm{C}$, Deschuttere $\mathrm{M}$, et al: $\mathrm{H}$ reflexes in muscles of the lower and upper limbs in man: Identification and clinical significance, in Desmedt JE (ed): Motor Control Mechanisms in Health and Disease. New York, Raven Press, 1983, pp 951-960

20. Draganich LF, Jaeger R, Kralj A: EMG activity of the quadriceps and hamstrings during monoarticular knee extension and flexion. Trans Orthop Res Soc 12: 283, 1987

21. Duncan $A M$, Wyrick $W$, Miller EL: Instrumentation for obtaining fractionated electromyographical response times to a joint displacement stimulus. Res Q 45: 452-459, 1974
22. duToit GT: Knee joint cruciate ligament substitution: The Lindemann procedure. S Afr J Surg 5: 25-30,1987

23. Eccles JC: Evolution of the brain: Creation of the self, in: Evolution of the Brain. New York, Routledge, 1989, pp 61-67

24. Eccles R, Lundberg A: Synaptic actions in motoneurones by afferents which may evoke the flexion reflex. Arch Ital Biol 97: 199-221, 1959

25. Ekholm J, Eklund G, Skoglund S: On the reflex effects from the knee joint of the cat. Acta Physiol Scand 50: 167-174, 1960

26. Fedina $L$, Hultborn $H$ : Facilitation from ipsilateral primary afferents of interneuronal transmission in the la inhibitory pathway to motoneurones. Acta Physiol Scand 86: 59-81, 1972

27. France EP, Paulos LE, Jayaraman G, et al: The biomechanics of lateral knee bracing. Part II: Impact response of the braced knee. Am J Soorts Med 15: $430-438,1987$

28. Fuchs AF, Anderson ME, Binder MD, et al: The neural control of movement, in Patton HD (ed): Textbook of Physiology. Philadelphia, WB Saunders Co, 1989, pp 503-509

29. Fukubayashi T, Torzilli PA, Sherman MF, et al: An in vitro biomechanical evaluation of anterior-posterior motion of the knee. J Bone Joint Surg 64A. 258-264, 1982

30. Girgis FG, Marshall JL, AI Monajem ARS: The cruciate ligament of the knee joint. Anatomical, functional and experimental analysis. Clin Orthop 106. 216-231, 1975

31. Goldfuss AJ, Morehouse CA, LeVeau BF: Effect of muscular tension on knee stability. Med Sci Sports 5: 267-271, 1973

32. Gomez-Barrena E, Munuera L, Martinez-Moreno E: Neural pathways of anterior cruciate ligament traced to the spinal ganglia. Trans Orthop Res Soc 17: 503,1992

33. Goslow G, Reinking R, Stuart D: The cat step cycle: Hind limb joint angles and muscle lengths during unrestrained locomotion. J Morphol 141: 1-42, 1973

34. Grigg P, Greenspan BJ: Response of primate joint afferent neurons to mechanical stimulation of knee joint. $J$ Neurophysiol $40: 1-8,1977$

35. Grigg $P$, Harrigan EP, Fogarty KE: Segmental reflexes mediated by joint afferent neurons in cat knee. J Neurophysiol 41: 9-14, 1978

36. Grigg P, Hoffman AH: Calibrating joint capsule mechanoreceptors as in vivo soft tissue load cells. J Biomech 22: 781-785, 1989

37. Hongo T, Jankowska $E$, Lundberg A: The rubrospinal tract. Il. Facilitation of interneuronal transmission in reflex paths to motoneurons. Exp Brain Res 7: 365-391, 1969

38. Hsieh HH, Walker PS: Stabilizing mechanisms of the loaded and unloaded knee joint. J Bone Joint Surg 58A: 87-93, 1976

39. Jonsson $\mathrm{H}$, Karrholm $\mathrm{J}$ : Kinematics of the weight-bearing knee with and without ACL injury. Trans Orthop Res Soc 17: 664, 1992

40. Kadaba MP, Wootten ME, Gainey J, et al: Repeatability of phasic muscle activity: Performance of surface and intramuscular wire electrodes in gait analysis. J Orthop Res 3: 350-359, 1985

41. Kennedy JC, Alexander IJ, Hayes KC: Nerve supply of the human knee and its functional importance. Am J Sports Med 10: 329-335, 1982

42. Kennedy JC, Weinberg HW, Wilson AS: The anatomy and function of the anterior cruciate ligament. As determined by clinical and morphological studies. J Bone Joint Surg 56A: 223-235, 1974

43. Kimura J: Electrodiagnosis in Diseases of Nerve and Muscle: Principles and Practice. Second edition. Philadelphia, FA Davis Co, 1989

44. Kowalk DL, Wojtys EM, Disher J, et al: Quantitative analysis of the measuring capabilities of the KT-1000 knee ligament arthrometer. Am J Sports Med 21: 744-747, 1993

45. Lass $P$, Kaalund $S$, leFevre $S$, et al: Muscle coordination following rupture of the anterior cruciate ligament. Electromyographic studies of 14 patients. Acta Orthop Scand 62: 9-14, 1991

46. Lewis JL, Shybut GT: In vivo forces in the collateral ligaments of canine knees. Trans Orthop Res Soc 6: 4, 1981

47. Lorentzon R, Elmqvist LG, Sjöström M, et al: Thigh musculature in relation to chronic anterior cruciate ligament tear: Muscle size, morphology, and mechanical output before reconstruction. Am J Sports Med 17: 423-429, 1989

48. Lundberg $A$, Malmgren $K$, Schomburg $E$ : Role of joint afferents in motor control exemplified by effects on reflex pathways from lb afferents. $J$ Physiol 284: 327-343, 1978

49. Malone TR, Hardaker WT, Garrett WE, et al: Relationship of gender in anterior cruciate ligament injuries in intercollegiate basketball players. $J$ South Orthop Assoc 2: 36-39, 1993

50. Markolf KL, Bargar WL, Shoemaker SC, et al: The role of joint load in knee stability. J Bone Joint Surg 63A: 570-585, 1981

51. Markolf $\mathrm{KL}$, Graff-Radford $\mathrm{A}$, Amstutz $\mathrm{HC}$ : In vivo knee stability. $J$ Bone Joint Surg 60A: 664-674, 1978

52. Markolf KL, Kochan A, Amstutz HC: Measurement of knee stiffness and laxity in patients with documented absence of the anterior cruciate ligament. J Bone Joint Surg 66A: 242-253, 1984

53. Markolf KL, Mensch JS, Amstutz HC: Stiffness and laxity of the knee: The contributions of the supporting structures. A quantitative in vitro study. $J$ Bone Joint Surg 58A: 583-594, 1976 
54. McDaniel WJ, Dameron TB: Untreated ruptures of the anterior cruciate ligament. J Bone Joint Surg 62A: 696-705, 1980

55. Miyashita $M$, Miura $M$, Matsui $H$, et al: Measurement of the reaction time of muscular relaxation. Ergonomics 15: 555-562, 1972

56. Noyes FR, Barber SD, Mangine RE: Bone-patellar ligament-bone and fascia lata allografts for anterior cruciate ligament reconstruction. J Bone Joint Surg 72A: 1125-1136, 1990

57. Noyes FR, Mooar PA, Matthews DS, et al: The symptomatic anterior cruciate-deficient knee. Part I: The long-term functional disability in athletically active individuals. J Bone Joint Surg 65A: 154-162, 1983

58. O'Connor BL, Visco DM, Brandt KD: Gait alterations in dogs with unstable knee joints: Evidence that the central nervous system is reprogrammed to protect unstable joints. Trans Orthop Res Soc 17: 478, 1992

59. Olmstead TG, Wevers HW, Bryant JT, et al: Effect of muscular activity on valgus/varus laxity and stiffness of the knee. J Biomech 19:565-577, 1986

60. Osternig LR, Robertson R, Troxel R, et al: Muscle activation during proprioceptive neuromuscular facilitation (PNF) stretching techniques. Am Phys Med 66: 298-307, 1987

61. Palmar I: Pathophysiology of the medial ligament of the knee joint. Acta Chir Scand 115: 312-318, 1958

62. Palmar I: Plastic surgery of the ligaments of the knee. Acta Chir Scand 91: $37-48,1944$

63. Petersen I, Stener B: Experimental evaluation of the hypothesis of ligamento-muscular protective reflexes. III. A study in man using the medial collateral ligament of the knee joint. Acta Physiol Scand 48(Suppl 166): $51-61,1958$

64. Pitman Mi, Nainzadeh N, Menche D, et ai: The intraoperative evaluation of the neurosensory function of the anterior cruciate ligament in humans using somatosensory evoked potentials. Arthroscopy 8: 442-447, 1992

65. Pope DF, Cole KJ, Brand RA: Physiologic loading of the anterior cruciate ligament does not activate quadriceps or hamstrings in the anesthetized cat. Am J Sports Med 18: 595-599, 1990

66. Pope MH, Johnson RJ, Brown DW, et al: The role of the musculature in injuries to the medial collateral ligament. J Bone Joint Surg 61A:398-402, 1979

67. Powers WR: Nervous system control of muscular activity, in Knuttgen $\mathrm{HG}$ (ed): Neuromuscular Mechanisms for Therapeutic and Conditioning Exercise. Baltimore, University Park Press, 1976, pp 1-30

68. Pratt H, Starr A, Amlie RN, et al: Mechanically and electrically evoked somatosensory potential in normal humans. Neurology 29: 1236-1244, 1979
69. Prochazka A: Proprioception during voluntary movement. Can J Physiol Pharmacol 64: 499-504, 1986

70. Renström P, Arms SW, Stanwyck TS, et al: Strain within the anterior cruciate ligament during hamstring and quadriceps activity. Am J Sports Med 14: 83-87, 1986

71. Schultz RA, Miller DC, Kerr CS, et al: Mechanoreceptors in human cruciate ligaments. A histological study. J Bone Joint Surg 66A: 1072-1076

72. Schutte MJ, Dabezies EJ, Zimny ML, et al: Neural anatomy of the human anterior cruciate ligament. J Bone Joint Surg 69A: 243-247, 1987

73. Solomonow $\mathrm{M}$, Baratta $\mathrm{R}$, Zhou $\mathrm{BH}$, et al: The synergistic action of the anterior cruciate ligament and thigh muscles in maintaining joint stability. Am J Sports Med 15: 207-213, 1987

74. Tibone JE, Antich TJ, Fanton GS, et al: Functional analysis of anterior cruciate ligament instability. Am J Sports Med 14: 276-284, 1986

75. Torg JS, Conrad W, Kalen V: Clinical diagnosis of anterior cruciate ligament instability in the athlete. Am J Sports Med 4: 84-93, 1976

76. Torzilli PA, Greenberg RL, Insall J: An in vivo biomechanical evaluation of anterior-posterior motion of the knee. J Bone Joint Surg 63A: 960-968, 1981

77. Torzilli PA, Panariello RA, Forbes A: Measurement reproducibility of two commercial knee test devices. J Orthop Res 9: 730-737, 1991

78. Walla DJ, Albright JP, McAuley E, et al: Hamstring control and the unstable anterior cruciate ligament-deficient knee. Am J Sports Med 13: 34-39, 1985

79. Wang CJ, Walker PS: Rotatory laxity of the human knee joint. J Bone Joint Surg 56A: $161-170,1974$

80. White AA, Raphael IG: The effect of quadriceps loads and knee position on strain measurements of the tibial collateral ligament. An experimental study on human amputation specimens. Acta Orthop Scand 43: 176-187, 1972

81. Wroble RR, Brand RA: Function of knee ligaments: A historical review of two perspectives. lowa Orthop $J$ 8: 67-72, 1988

82. Wroble RR, Van Ginkel LA, Grood ES, et al: Repeatability of the KT-1000 arthrometer in a normal population. Am J Sports Med 18: 396-399, 1990

83. Wu CD, Birac D, Andriacchi TP, et al: A study of compensatory function in ACL-deficient knees in walking and more stressful activities. Trans Orthop Res Soc 17: 659, 1992

84. Yasuda $K$, Erickson AR, Johnson RJ, et al: Dynamic strain behavior in the medial collateral and anterior cruciate ligaments during lateral impact loading. Trans Orthop Res Soc 17: 127, 1992 